\title{
Analisis Quality Control Koreksi Blending BBM Jenis Premium dan Pertalite
}

\section{Quality Control Analysis on Blending of Premium and Pertalite Fuels}

\author{
Silvia*, Gudi Yenti Br. Munthe, Dewi Diniaty, Muhammad Rizki, Muhammad Nur \\ Jurusan Teknik Industri, Fakultas Sains dan Teknologi, UIN Sultan Syarif Kasim Riau \\ Jl. HR. Soebrantas No. 155 Simpang Baru, Panam, Pekanbaru, 28293 \\ Email: silvia@uin-suska.ac.id, gudiyenty@gmail.com, dewidiniaty@uin-suska.ac.id
}

\begin{abstract}
ABSTRAK
Studi Kasus ini dilakukan pada a perusahaan pengolahan minyak bumi dan gas. Perusahaan ini memproduksi Bahan Bakar Minyak jenis premium dan pertalite. Blending Bahan Bakar Minyak jenis premium dan pertalite adalah proses pencampuran light naphta terhadap produk jadi yang telah selesai diproduksi. Blending bertujuan untuk mendapatkan nilai oktan yang optimal sehingga didapatkan nilai oktan yang sesuai dengan mesin kendaraan. jenis premium mendominasi nilai oktan saat awal produksi sebesar 88.8 .sehingga, ini perlu dilakukan koreksi agar oktan tersebut berubah menjadi 88.0 agar mesin dapat melakukan pembakaran. kemudian, pertalite memiliki nilai oktan 90.4 pada saat awal produksi dan perlu dilakukan blending agar nilai oktannya menjadi 90.0. penelitian ini melakukan analisis quality control untuk koreksi blending produk antara lain dari segi: faktor operator atau manusia, peralatan atau mesin, material, metode dan lingkungan.
\end{abstract}

Kata Kunci: Blending, Premium, Pertalite, Quality Control

\section{ABSTRACT}

This case study was conducted at a petroleum and gas processing company. This company produces premium types of fuel oil and pertalite. Blending of premium and pertalite fuel oils is the process of mixing light naphta to finished products that have been produced. Blending aims to get the optimal octane value so that it gets an octane value that matches the vehicle engine. the premium type dominates the octane value at the start of production at 88.8. Thus, this needs to be corrected so that the octane changes to 88.0 so that the engine can burn. then, pertalite has an octane value of 90.4 at the beginning of production and needs to be blended so that the octane value becomes 90.0. This research conducts quality control analysis for correction of product blending, among others in terms of: operator or human factors, equipment or machinery, materials, methods and environment.

Keyword: Blending, Premium, Pertalite, Quality Control

\section{Pendahuluan}

Perkembangan dunia perindustrian yang semakin pesat hingga saat ini tidak terlepas dari sektor migas (minyak bumi dan gas) sebagai salah satu bidang energi dan sumber daya mineral yang merupakan objek vital nasional. Dengan adanya sektor migas akan memberikan kemudahan bagi semua orang untuk memperoleh kebutuhan. Jika sektor migas tidak ada, maka akan terjadi kelumpuhan dalam aktivitas di berbagai sektor kehidupan. Keberadaan migas akan mampu menciptakan hal positif yang memajukan sektor industri dalam cakupan wilayah sehingga dapat memberikan keuntungan yang besar bagi kehidupan bernegara guna meningkatkan kualitas hidup masyarakat.

Banyaknya kebutuhan aktivitas yang memerlukan energi membuat minyak bumi begitu sangat penting dalam kehidupan sehari-hari. Minyak bumi merupakan komoditas strategis yang menjadi sumber energi bagi perputaran roda perekonomian semua negara (Ma'arif, 2014).

Bahan bakar minyak (BBM) adalah energi yang terbentuk dari fosil dalam perut bumi yang tidak dapat diperbaharui. Yang termasuk dari komoditas BBM adalah Avgas (Aviation gasoline), Avtur (Aviation Turbine), Bensin, Minyak tanah (Kerosene), Minyak solar, Minyak diesel, Minyak bakar, Biodiesel dan Pertamina Dex. Dari sekian 
banyak bahan bakar minyak (BBM), bensin dan solar merupakan BBM yang paling vital fungsinya. Di zaman modern ini, mobilitas manusia sangat tinggi, sehingga vitalnya bensin bagi perekonomian suatu negara sama vitalnya dengan darah bagi tubuh manusia. Karena tanpa bensin dan minyak solar dunia yang kita tempati ini seperti akan berhenti berdenyut (Latif, 2015).

Bahan bakar minyak adalah bahan bakar yang berasal dan/atau diolah dari minyak bumi. Berdasarkan Undang-Undang No.8 tahun 1971, Pertamina sebagai satu-satunya perusahaan milik negara yang ditugaskan oleh pemerintah melaksanakan pengusahaan migas mulai dari mengelola dan menghasilkan migas dari ladangladang minyak di seluruh Indonesia. Mengolahnya dan menyediakan serta melayani kebutuhan bahan bakar minyak di seluruh Indonesia (Remus dkk, 2018).

Bahan bakar minyak jenis premium dan pertalite yang digunakan untuk kendaraan adalah jenis BBM yang memiliki nilai oktan 88,0 untuk jenis premium dan 90,0 untuk jenis pertalite. Jika nilai oktannya lebih tinggi, akan mengakibatkan mesin tidak dapat melakukan pembakaran. Oleh sebab itu dilakukan pencampuran antara produk jadi dengan bahan lain untuk menurunkan nilai oktan sehingga produk dapat dipasarkan. Sebaliknya, jika nilai oktan rendah mengakibatkan BBM mudah terbakar dan pastinya berbahaya.

Koreksi blending adalah kegiatan pencampuran light naphta terhadap produk jadi yang telah selesai diproduksi yang bertujuan untuk menurunkan nilai oktan yang tinggi agar mendapatkan nilai oktan yang sesuai dengan mesin kendaraan. Jika tidak dilakukan koreksi blending, akibatnya PT. XYZ Dumai akan mengalami kerugian karena produk yang dihasilkan tidak dapat melakukan pembakaran di mesin kendaraan sehingga tidak dapat dipasarkan ke masyarakat.

Pada umumnya koreksi blending juga berdampak pada volume akhir yang bertambah. Sehingga setelah dilakukan koreksi blending, maka akan diperoleh oktan yang sesuai dengan mesin kendaraan dan volume bertambah sehingga PT.XYZ Dumai memperoleh keuntungan akibat dilakukannya koreksi blending tersebut. Koreksi blending premium dan pertalite dilakukan dengan Light Naphta dengan tingkat 70-71, Light Naphta adalah bahan untuk pencampuran proses blending.

PT.XYZ Dumai merupakan perusahaan besar yang memiliki kualitas minyak dengan hasil yang baik karena kualitas minyak yang baik pasti berasal dari proses dan sesuai dari prosedur dan standar kualitas yang telah ditentukan. Menurut Wresni, A. dkk., (2019), bahwa salah satu penyebab kualtas dari produk dikaenakan proses produksinya tidak mengikuti SOP yang telah ditentukan. menjelaskan bahawa Penyebab terjadinya koreksi blending produk antara laindari segi: faktor operator atau manusia, peralatan atau mesin, material, metode dan lingkungan. Akibat dari koreksi blending produk pada proses pembuatan minyak dapat berdampak positif pada volume yang dihasilkan dan Oktan yang sesuai. Oleh karena itu, perlu dilakukan identifikasi terjadinya koreksi blending produk.(Annisa \& Setiawan, 2018).

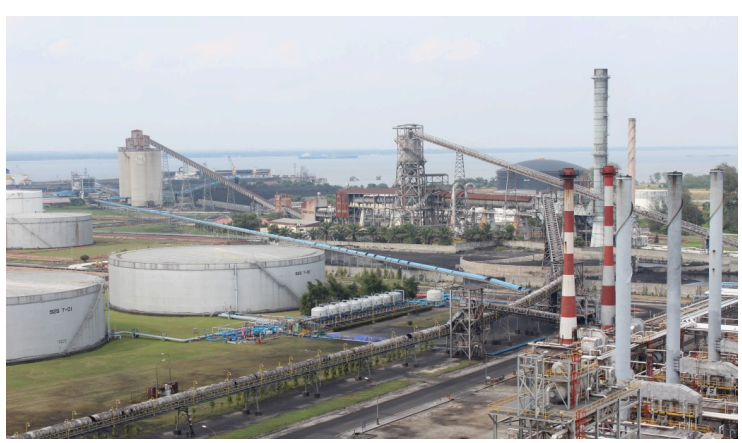

Gambar 1. Salah satu kilang di PT. XYZ Dumai

Untuk menganalisis koreksi blending produk terhadap premium dan pertalite maka diperlukan konsep quality control untuk mengidentifikasi terjadinya proses koreksi blending produk pada unit proses produksi kilang di PT. XYZ Dumai. Quality control adalah kualitas barang atau jasa dapat berkenaan dengan keandalan, ketahanan, waktu yang tepat, penampilannya, integritasnya, kemurniannya, individualitasnya, atau kombinasi dari berbagai faktor tersebut (Devani \& Wahyuni, 2016). Lebih lanjut dalam (Anggraini dkk., 2019) menjelaskan bahawa

\section{Metode Penelitian}

Tahapan penelitian dipaparkan pada flowchart di bawah ini (gambar 2).

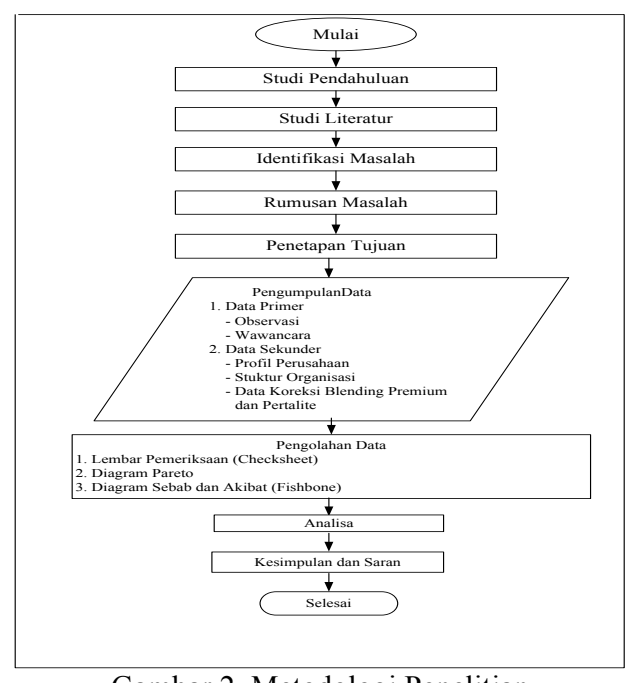

Gambar 2. Metodologi Penelitian 


\section{Hasil dan Pembahasan}

\section{Spesifikasi BBM jenis premium dan Pertalite}

a. Premium

Premium adalah bahan bakar mesin bensin yang memiliki angka oktan 88 . Premium digunakan untuk bahan bakar kendaraan bermotor mesin bensin dengan resiko kompresi $9: 10$.

Tabel 1. Spesifikasi Produk Premium

\begin{tabular}{|l|c|}
\hline \multicolumn{1}{|c|}{ Spesifikasi } & Klasifikasi \\
\hline Density & $715-770$ \\
\hline Stabilitas Oksidasi & 360 menit \\
\hline Dist $10 \%$ & Max 74 \\
\hline Dist $50 \%$ & $75-125$ \\
\hline Dist 90\% & Max 180 \\
\hline End Point & Max 215 \\
\hline Residue & Max 2.0 \\
\hline Dye content & Max 0.13 \\
\hline Existent Gum & Max 5 \\
\hline Induction Period & Min 360 \\
\hline Lead content (Pb) & Max 0.013 \\
\hline Mercaptane Sulphur & Max 0,002 \\
\hline RVP & $45-69$ \\
\hline RON & Min 88.0 \\
\hline Sediment & Max 1 \\
\hline Sulphur Content & Max 0,05 \\
\hline Unwashed Gum & Max 70 \\
\hline Washe Gum & Max 5 \\
\hline Copper Strip & Class 1 \\
\hline
\end{tabular}

(Sumber : Arsip PT. XYZ Dumai, 2020) b. Pertalite

Pertalite adalah BBM yang memilki angka oktana 90.Pertalite berwarna hijau terang dan digunakan untuk bahan bakar kendaraan bermotor.

Tabel 2. Spesifikasi Produk Pertalite

\begin{tabular}{|l|c|}
\hline \multicolumn{1}{|c|}{ Spesifikasi } & Klasifikasi \\
\hline RON & Min 90.0 \\
\hline Stabilitas Oksidasi & 360 menit \\
\hline Sulphur Content & 0,05 \\
\hline Injeksi Pb & Tidak diizinkan \\
\hline Kandungan Oksigen & $2,7 \%$ \\
\hline Dist $10 \%$ & Max 74 \\
\hline Dist $50 \%$ & $88-125$ \\
\hline Dist $90 \%$ & Max 180 \\
\hline End Point & Max 215 \\
\hline Residue & $2.0 \%$ \\
\hline Sedimen & Max $1 \mathrm{mg} / \mathrm{L}$ \\
\hline Unwashed Gum & Max 70 \\
\hline Washed Gum & Max 5 \\
\hline RVP & $45-69 \mathrm{kPa}$ \\
\hline Density & $715-770$ \\
\hline Copper Strip & Class 1 \\
\hline Sulphur Mercapten & Max 0,002 \% \\
\hline Kandungan Pewarna & Max 0,13 g /100 L \\
\hline
\end{tabular}

(Sumber :Arsip PT XYZ Dumai, 2020)

Berikut ini adalah 3 koreksi blending produk premium dan pertalite dalam rentang tahun 20192020 berdasarkan pengambilan data langsung yang dilakukan di Departemen RP\&O (Refinery Planning \& Optimization) PT. XYZ Dumai:

Tabel 3. Data Koreksi Blending 2019- 2020 di Kilang Refinery Unit II PT. XYZ Dumai

\begin{tabular}{|c|c|c|c|c|c|c|c|}
\hline \multirow{2}{*}{ No. } & \multicolumn{2}{|c|}{ Koreksi Blending } & \multirow{2}{*}{ Tangki } & \multicolumn{4}{|c|}{ Transfer } \\
\cline { 8 - 9 } \cline { 6 - 8 } & Produk & $\begin{array}{c}\text { Jumlah } \\
\text { Kiloliter })\end{array}$ & & Tangki & $\begin{array}{c}\text { Mixer } \\
(\text { Jam })\end{array}$ & $\begin{array}{c}\text { Kapasitas } \\
\text { Transfer (mm) }\end{array}$ & Oktan \\
\hline 1. & PREMIUM & 3000 & 07 & 12 & \pm 2 & 220 & 88.8 \\
\hline 2. & PERTALITE & 8750 & 07 & 28 & \pm 3 & 450 & 90,4 \\
\hline 3. & PERTALITE & 8750 & 07 & 28 & \pm 3 & 160 & 90,4 \\
\hline
\end{tabular}

(Sumber : Pengumpulan data PT.XYZ Dumai, 2020)

Tabel 4. Koreksi Blending Produk Premium dan Pertalite

\begin{tabular}{|c|l|}
\hline No. & \multicolumn{1}{|c|}{$\begin{array}{c}\text { Koreksi Blending Produk Premium dan } \\
\text { Pertalite }\end{array}$} \\
\hline 1. & $\begin{array}{l}\text { Produksi produk premium } \\
\text { 3000 Kiloliter di Tangki-12 } \\
\text { Dengan Oktan 88,8 } \\
\text { Koreksi Oktan } 88,0\end{array}$ \\
\hline 2. & $\begin{array}{l}\text { Produksi produk pertalite } \\
8750 \text { Kiloliter di Tangki-12 } \\
\text { Dengan Oktan 90,4 } \\
\text { Koreksi Oktan 90,0 }\end{array}$ \\
\hline 3. & Produksi produk pertalite \\
\hline
\end{tabular}

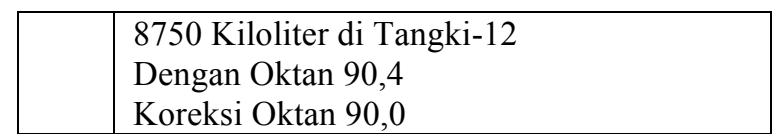

(Sumber : Pengumpulan data PT. XYZ Dumai 2020)

Dari data pada Tabel 3. Terlihat nilai oktan pada produk jadi masih tinggi yaitu 88,8 untuk BBM jenis premium dan 90,4 untuk BBM jenis pertalite. Oleh karena itu diperlukan koreksi blending agar didapatkan nilai oktan optimal. 


\section{Quality Control}

Adapun pengolahan data menggunakan Quality Control dalam proses produksi minyak di PT. XYZ Dumai adalah sebagai berikut :

\section{Lembar Pemeriksaan (CheckSheet)}

Berikut alat pengendalian kualitas lembar pemeriksaan (checksheet) pada stasiun koreksi blending premium.

Tabel 5. Lembar Check Sheet Stasiun Koreksi Blending Premium

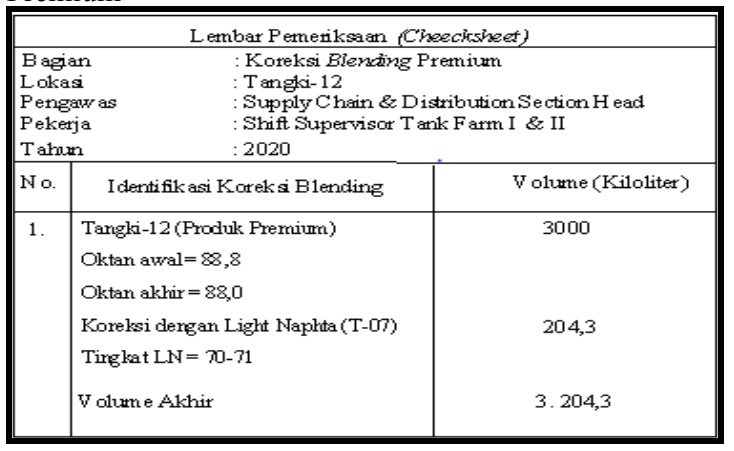

Dari tabel diatas tersebut dapat diketahui bahwa pada produk jenis BBM yaitu premium. Blending Premium menggunakan Naphta (70-71) estimasi total nilai volumenya sebesar $3.204,3$ KL. Nilai tersebut menjelaskan bertambahnya volume dari sebelumnya.

Berikut alat pengendalian kualitas lembar pemeriksaan (checksheet) pada stasiun koreksi blending pertalite.

Tabel 6. Lembar Check Sheet Stasiun Koreksi Blending Pertalite

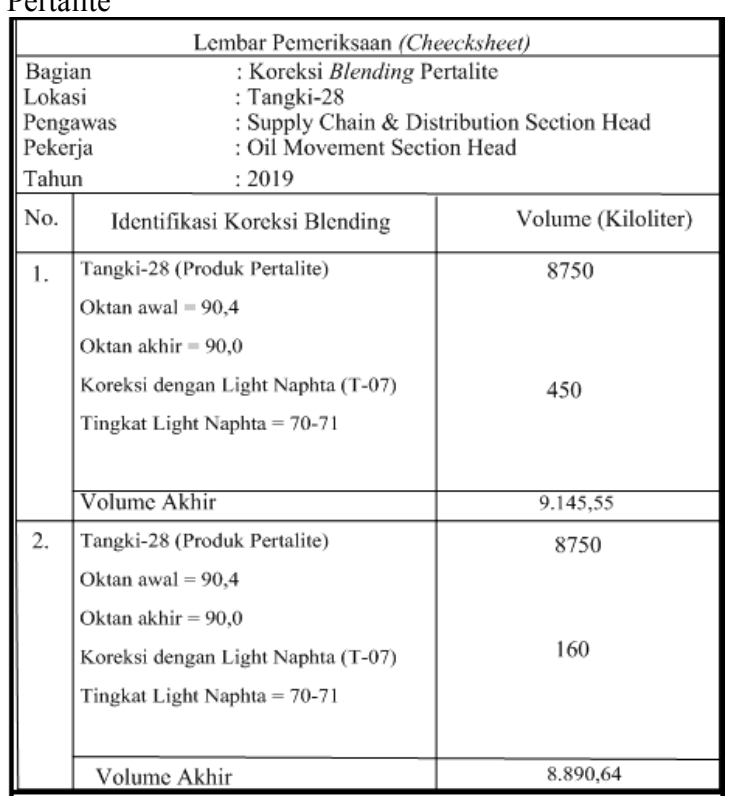

\section{Diagram Pareto}

Tabel 7. Persentase koreksi blending

\begin{tabular}{|c|c|c|c|c|}
\hline No & $\begin{array}{c}\text { Jenis } \\
\text { Koreksi } \\
\text { Produk }\end{array}$ & $\begin{array}{c}\text { Jumlah } \\
\text { (Kiloliter) }\end{array}$ & $\begin{array}{l}\text { Persen } \\
\text { tase }\end{array}$ & $\begin{array}{l}\text { Persentase } \\
\text { Kumulatif }\end{array}$ \\
\hline 1 & $\begin{array}{l}\text { Koreksi } \\
\text { Blending } \\
\text { Pertalite } \\
450 \mathrm{~mm} \text { di } \\
\text { Tangki-28 }\end{array}$ & $9.145,55$ & $\begin{array}{c}43,058 \\
\%\end{array}$ & $43,058 \%$ \\
\hline 2 & $\begin{array}{l}\text { Koreksi } \\
\text { Blending } \\
\text { Pertalite } \\
160 \mathrm{~mm} \text { di } \\
\text { Tangki-28 } \\
\end{array}$ & $8.890,64$ & $\begin{array}{c}41,857 \\
\%\end{array}$ & $84,915 \%$ \\
\hline 3 & $\begin{array}{l}\text { Koreksi } \\
\text { Blending } \\
\text { Premium } \\
220 \mathrm{~mm} \\
\text { Tangki-12 }\end{array}$ & $3.204,3$ & $\begin{array}{c}15,085 \\
\%\end{array}$ & $100 \%$ \\
\hline \multicolumn{2}{|c|}{ Total } & 21.240 .49 & $100 \%$ & \\
\hline
\end{tabular}

Dengan persentase masing-masing sebesar Koreksi Blending Premium Tangki-12 sebesar $15,085 \%$, Koreksi Blending Pertalite $450 \mathrm{~mm}$ di Tangki-28 sebesar 43,058 \% dan Koreksi Blending Pertalite $160 \mathrm{~mm}$ di Tangki-28 sebesar 41,857\%. Ketiga koreksi blending produk yang terjadi harus segera dilakukan tindakan perbaikan guna meningkatkan volume dan harga produk.

Berdasarkan data di tabel 7, maka dapat digambarkan diagram pareto yaitu untuk mengidentifikasi masalah utama untuk meningkatkan volume dan harga produk dari yang paling besar ke yang paling kecil.

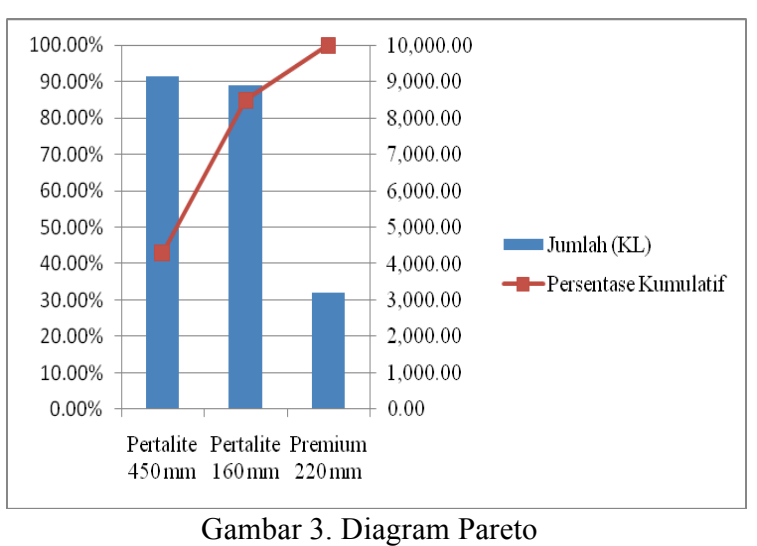

Adapun analisa persentase blending produk jenis BBM Periode tahun 2020 dilakukan untuk mengetahui berapa tingkat persen koreksi blending produk dan volume yang dihasilkan. Persentase produk akan berdampak pada seberapa besar volume premium dan pertalite ketika Oktan telah berubah guna meningkatkan keuntungan perusahaan. Persentase tersebut berguna dalam 
mengidentifikasi koreksi utama untuk meningkatkan volume produk agar memberikan keuntungan atau margin yang lebih tinggi dari yang paling besar ke yang paling kecil.

Selanjutnya analisa untuk diagram pareto menjelaskan persentase jumlah volume setelah dikoreksi yang tertuang dalam bentuk grafik untuk memudahkan dalam melihat data hasil koreksi akhir.

\section{Fishbone}

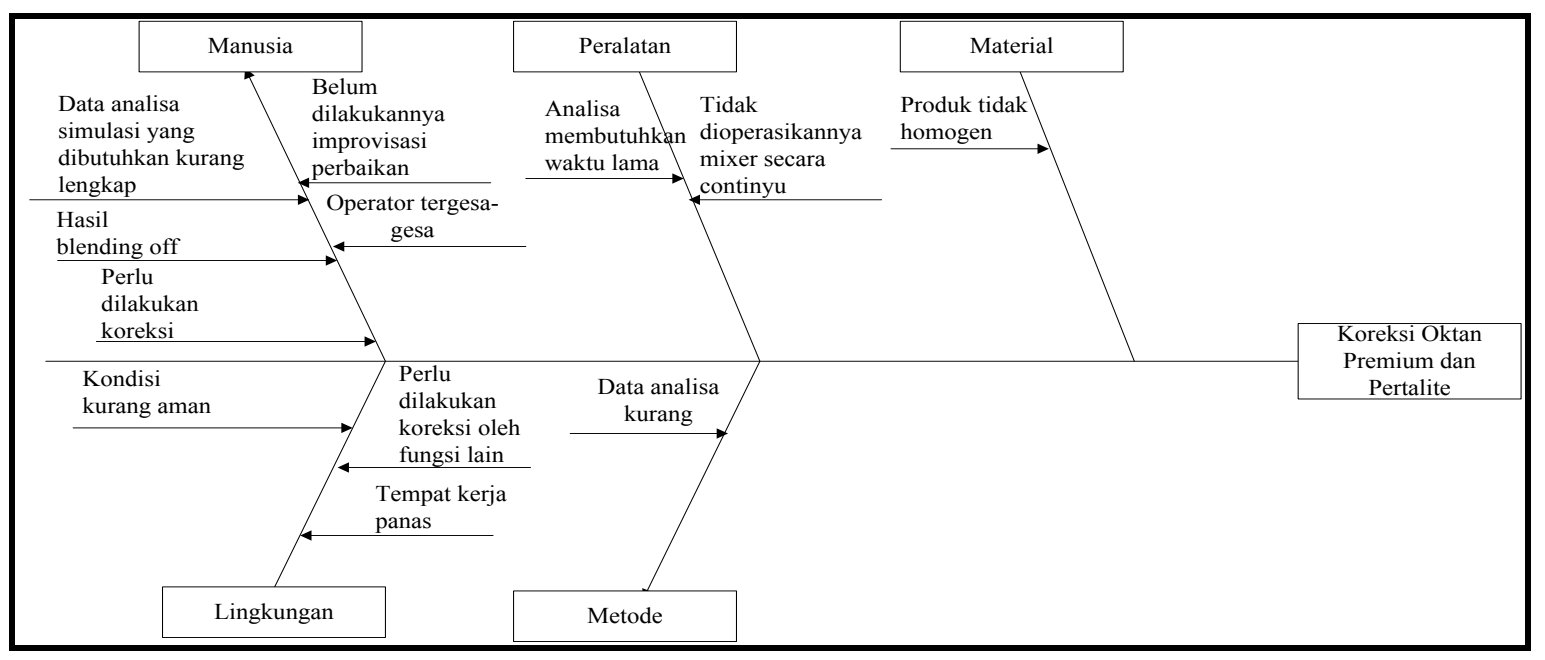

Gambar 4. Diagram Fishbone

\section{Kesimpulan}

Lembar pemeriksaan premium identifikasi terhadap Oktan 88,8 menjadi 88,0 yang dilakukan di bagian koreksi blending premium di Tangki 12, dengan pengawas supply chain and distribution section head dan pekerja shift supervisor tank farm I dan II dengan estimasi jumlah tansfer $220 \mathrm{~mm}$. Volume awal 3000 Kiloliter sehingga volume akhirnya menjadi 3.204,3 Kiloliter.

Sedangkan pertalite identifikasi terhadap Oktan 90,4 menjadi 90,0 yang dilakukan di bagian koreksi blending pertalite di Tangki 28, dengan pengawas supply chain and distribution section head dan pekerja oil movement section head dengan estimasi jumlah transfer $450 \mathrm{~mm}$. Volume awal 8750 Kiloliter sehingga volume akhirnya menjadi 9.145,4 Kiloliter.

Lembar pemeriksaan pertalite dentifikasi terhadap Oktan 90,4 menjadi 90,0yang dilakukan di bagian koreksi blending pertalite di Tangki 28, dengan pengawas supply chain and distribution section head dan pekerja oil movement section head
Untuk mengetahui penyebab dan koreksi blending produk, maka dianalisa menggunakan diagram sebab akibat. Berikut ini adalah diagram sebab akibat untuk koreksi blending premium dan pertalite. Koreksi tersebut dianalisa menggunakan diagram sebab akibat (fishbone)

Diagram sebab akibat (fishbone) terkait tingkat lebihnya nilai Oktan yang berakibat pada volume dan margin produk di RU II akan dianalisa lebih dalam menggunakan diagram sebab akibat (fishbone). Diagram sebab akibat (fishbone) yang dominan diperoleh dari manusia dan alat. 


\section{Daftar Pustaka}

Annisa, M.R., \& Setiawan. W. (2018) Menganalisis Defect Sanding Mark Unit Pick Up Tmc Dengan Metode Seven Tools Pt. Adm. Jurnal Integrasi Sistem Industri.

Latif, A. (2015). Dampak Fluktuasi Harga Bahan Bakar Minyak Terhadap Suplai Sembilan Bahan Pokok di Pasar Tradisional”. Jurnal Al-Buhuts Vol. 11 No. 1.

Ma'arif, S. (2014). Kebijakan Perminyakan Nasional : Dari Kendali Negara Menuju Kapitalisme Pasar. Jurnal Administrasi Negara.

Remus, S., Panggabean, \& P, Siregar, S. (2018). Analisis Pengaruh Perubahan Harga Bahan Bakar Minyak Premium dan Solar Di Kota Medan. Jurnal Ilmiah Methonomi.

Devani, V. \& Wahyuni, F. (2015). Pengendalian Kualitas Kertas Dengan Menggunakan Statistical Process Control di Paper Machine 3. Jurnal Ilmiah Teknik Industri.

Anggraini, W., Kusumanto, I., Sutaryono (2019). Usulan Peningkatan Kualitas Kain Batik Semi Tulis menggunakan Metode Six Sigma. Jurnal Hasil Penelitian dan Karya Ilmiah dalam Bidang Teknik Industri, Vol 5. No. 1, 2019. 